\title{
Doping Manganese Oxides with Ceria and Ceria Zirconia Using a One-Pot Sol-Gel Method for Low Temperature Diesel Oxidation Catalysts
}

\author{
Ruairi O'Donnell ${ }^{1} \cdot$ Kathryn Ralphs $^{1} \cdot$ Maxime Grolleau $^{1} \cdot$ Haresh Manyar $^{1} \cdot$ Nancy Artioli $^{1} \mathbb{C}$
}

Published online: 2 March 2020

(c) The Author(s) 2020

\begin{abstract}
Octahedral molecular sieves (OMS-2) are an interesting form of manganese oxide with a $2 \times 2$ edge sharing tunnel structure and a cation positioned inside. Cryptomelane is an OMS- 2 material with $\mathrm{K}^{+}$cations within the crystalline tunnel and has been widely used in catalytic oxidation reactions, due to a mixed valency of $\mathrm{Mn}^{3+}$ and $\mathrm{Mn}^{4+}$ cations. Cryptomelane (K-OMS-2) can be modified by structural incorporation of various dopants and tunnel cations which can enhance the catalytic activity of the material. It also offers to be a promising alternative material for the low temperature emission control of combustion vehicles; particularly during cold start and low temperature conditions of diesel vehicles. In this work we used a one-pot solgel route to synthesize a range of manganese oxide based supports doped with $\mathrm{Ce}$ and $\mathrm{CeZrO}_{2}$, as alternative low temperature diesel oxidation catalysts. We have investigated the combination of manganese, ceria and zirconia in mixed oxide catalyst supports. The synthesized samples were loaded with $1 \mathrm{wt} \% \mathrm{Pt}$ and their activity in the oxidation reactions of $\mathrm{CO}$ and $\mathrm{C}_{3} \mathrm{H}_{6}$, were compared with a commercial diesel oxidation catalyst with the same metal loading. The reductions in $\mathrm{CO}$ and $\mathrm{C}_{3} \mathrm{H}_{6}$ oxidation temperature $\mathrm{T}_{50}$ of $109 \mathrm{~K}$ and $81 \mathrm{~K}$ respectively was achieved compared to a commercial diesel oxidation catalyst.
\end{abstract}

Keywords Manganese oxides $\cdot$ OMS- $2 \cdot$ Ceria $\cdot$ Emission control $\cdot$ DOC $\cdot$ CO oxidation

\section{Introduction}

Ceria is the most plentiful rare earth metal on the planet and has been largely exploited for the effective use in catalytic redox reactions. It has been widely used as an industrial redox catalyst in automotive emission control, VOC oxidation and water gas shift reaction to name a few [15, 20, $24,32,34]$. One of the most common uses of ceria based materials is in automotive catalytic convertors. They have been traditionally used as supporting materials in three-waycatalysts (TWC), diesel oxidation catalysts (DOC) and soot combustion $[4,29,31]$. This has been largely attributed to

Electronic supplementary material The online version of this article (https://doi.org/10.1007/s11244-020-01250-x) contains supplementary material, which is available to authorized users.

Nancy Artioli

n.artioli@qub.ac.uk

1 School of Chemistry and Chemical Engineering, Queen's University Belfast, David Keir Building, 39-123 Stranmillis Rd, Belfast BT9 5AG, UK the redox properties and oxygen storage component (OSC) of ceria, with the ability to repeatedly change between oxidised and reduced states of $\mathrm{Ce}^{4+}$ and $\mathrm{Ce}^{3+}$. The reduction of the support also results in the formation of oxygen vacancies which are known to promote the activity of the material [25]. This allows ceria to absorb $\mathrm{O}^{2-}$ from its environment and release it again, to facilitate oxidation of vehicle exhaust gases, particularly in transient rich and lean conditions [27]. Although ceria is a very useful catalytic material, it can be prone to morphological changes when exposed to high temperatures. Through the growth of the crystallites through sintering, the surface area is reduced and thus, the redox properties deteriorate. The addition of zirconia to ceria has proved to increase the OSC compared to pure ceria. This has been attributed to the structural defects which are imposed in the material by the addition of $\mathrm{Zr}^{4+}$, which has a smaller ionic radius than $\mathrm{Ce}^{4+}$. These distortions of the ceria lattice, improves the mobility of oxygen through the bulk material, providing more available oxygen to participate in oxidation reactions at the surface $[27,29]$. The introduction of zirconia to ceria, forming a mixed oxide material, has been 
an important advancement in automotive emission control catalysis [3].

Manganese oxide based materials have also gained attention for high catalytic activity in redox reactions. They have been studied for the catalytic oxidation of soot from the exhaust stream of diesel vehicles and also as a catalyst support in the catalytic oxidation of NO [1]. They have also been widely studied for the oxidation of $\mathrm{CO}$ and VOCs which are other typical species emitted form mobile combustion engines [1, 12, 13, 18, 28, 36, 37]. Octahedral molecular sieves (OMS) are a crystalline form of manganese oxide. OMS materials with a $2 \times 2$ edge sharing tunnel structure are known as OMS-2 and are extensively applied for its moderate cost and low environmental impact. Various OMS-2 materials are known and are defined by the cation which is positioned within the tunnel structure. Hollandite is an OMS- 2 material containing $\mathrm{Ba}^{+}$, while cryptomelane contains $\mathrm{K}^{+}$cations within its tunnel structure and has a composition of $\mathrm{KMn}_{8} \mathrm{O}_{16}$ [11]. Due to the mixed valence of the manganese combined with the high surface area of amorphous manganese oxide, the material has excellent oxygen mobility and can easily form oxygen vacancies, which is a desirable property for an effective oxidation catalyst [6]. Different routes have been used for the synthesis of cryptomelane (K-OMS-2); including sol-gel, reflux and hydrothermal methods. Comparisons of the various techniques used to synthesise K-OMS-2, as described in literature, report that materials synthesised using a sol-gel method have the largest surface area and least crystalline structure [2, 9, 39]. The modification of OMS-2 materials through the addition of dopants has been studied in order to enhance its catalytic capabilities [22]. Ceria is one dopant which has been used to enhance OMS-2 due to its redox and OSC properties and has been used to substitute $\mathrm{K}^{+}$tunnel cations in $\mathrm{K}-\mathrm{OMS}-2$ $[16,38]$. Different modification methods have been reported, including the incorporation of ceria in the OMS-2 structure for the oxidation of various hydrocarbons and CO. Yu et al. reported that the addition of ceria reduced the crystal size of K-OMS-2 and increased the surface area, resulting in a reduction of dimethyel ether (DME) combustion light-off temperature [38]. It was also reported by Hapeshi et al. that when K-OMS-2 synthesised using a sol-gel method was doped with Cerium using potassium ion-exchange method, the cations would begin to replace the manganese within the OMS-2 framework [16]. Wang et al. also showed that the incorporation of ceria in the synthesis process, would result in a hindrance of the tunnel structure formation due to the distortions created by the larger $\mathrm{Ce}^{4+}$ cations [35].

Ceria and manganese oxide based materials are commonly used as supporting materials for redox catalysts, such as Nobel metals, due to their participation in the reaction mechanism. Traditionally, cerium zirconium oxide, has been used for automotive emission control catalysts; in particular three-way catalysts and diesel oxidation catalysts for the oxidation of $\mathrm{CO}$ and HCs [30]. Noble metals have been widely studied and used in the application redox catalysts. The use of $\mathrm{Pt}, \mathrm{Pd}$ and $\mathrm{Rh}$ and are considered to provide the active sites on which many oxidation reactions occur through the reduction of their oxides. Due to the low operating temperatures of diesel combustion engines, typically between 473 and $573 \mathrm{~K}$, the required noble metal loading on diesel oxidation catalyst can be up to three times higher than on a three-way catalyst [31]. This is undesirable as the cost of nobel metals is already high. Therefore, one approach in the development of such catalysts is to improve the activity of the support and interaction between the metal and the support.

As discussed in the previous paragraph, diesel engines operate at relatively low temperatures which are higher than the typical activation temperature of a typical diesel oxidation catalyst (DOC). Therefore, it is important that to find a catalyst with a light-off temperature which is lower than the operating temperature of the diesel engine, without the need for higher noble metal loading. Much work has been done to improve the efficiency of the metal loading on DOCs. Kim et al. synthesised a $\mathrm{ZrO}_{2}$ and $\mathrm{SiO}_{2}$ mixed oxide support using a sol-gel method. They reported the improved metal dispersion and improved resistance to hydrothermal ageing and sulphur poisoning and CO light-off at around $473 \mathrm{~K}$ [21]. Huang et al. investigated the promoting effect of loading a cerium zirconium oxide support with both platinum and vanadium. They reported a $\mathrm{CO} \mathrm{T}_{50}$ of around $493 \mathrm{~K}$ over a Pt (1 wt\%) $\mathrm{Ce}_{0.75} \mathrm{Zr}_{0.25}$ catalyst and a decrement of approximately $30 \mathrm{~K}$, through the addition of vanadium. A similar effect on $\mathrm{C}_{3} \mathrm{H}_{6}$ light-off was also reported [17]. Tang et al. carried out the in situ growth of ceria nano flakes on a cordierite monolith and compared the catalytic activity with a conventional DOC catalyst washcoat, showing an improvement of material use efficiency. Platinum was loaded on the ceria nanoflakes by Atomic layer deposition and $\mathrm{CO}$ and $\mathrm{C}_{3} \mathrm{H}_{6} \mathrm{~T}_{50}$ values of around $323 \mathrm{~K}$ and $333 \mathrm{~K}$ respectively, were reported [33]. As previously mentioned, manganese oxide based catalysts have been reported for NO and soot oxidation. However, few studies have been carried out on the performance of such materials in the catalytic oxidation of reactants in a complex diesel exhaust mixture. Although a recent publication by Lanvande, More and More on the catalytic activity of a $\mathrm{MnO}_{2}-\mathrm{CeO}_{2}$ catalysts which had been doped with $\mathrm{Mg}$, reported $50 \% \mathrm{CO}$ conversion at $377 \mathrm{~K}$ using a simplified diesel exhaust simulation [23]. This opens up the prospect of using similar materials as integrated diesel catalysts.

In this work, we have synthesised mixed oxide catalysts, combining ceria and cerium zirconium oxide with manganese oxide using a sol-gel method, for low temperature $\mathrm{CO}$ and $\mathrm{C}_{3} \mathrm{H}_{6}$ oxidation. The mixed oxide catalysts were 
characterised to understand the effect that combining the materials has on the structure and morphology of the materials. Light-off experiments were carried out, replicating the feed conditions typically associated with those of a light duty diesel vehicle. The catalysts were benchmarked by comparing the $\mathrm{CO}$ and $\mathrm{C}_{3} \mathrm{H}_{6}$ light-off temperatures achieved over each sample. The most active samples were loaded with $1 \mathrm{wt} \%$ Pt before comparing their catalytic performance with a model automotive catalyst, which was commercially sourced.

\section{Experimental Methods}

\subsection{Material Synthesis}

Sol-gel method as described by Ching et al. [9] was used to prepare K-OMS-2 samples, using maleic acid (Sigma Aldrich) and $\mathrm{KMnO}_{4}$ (Alfa Aesar). $\mathrm{KMnO}_{4}$ was dissolved in deionised water prior to slowly adding maleic acid. The solution was continuously stirred for either $40 \mathrm{~min}$ or $60 \mathrm{~min}$. The synthesised catalysts are denoted as OMS-2:X, where $\mathrm{X}$ is the stirring time in minutes. After stirring, the resulting gel was given time to settle before the top aqueous layer was decanted off. The gel was then washed four times; deionised water was added and the mixture was stirred for approximately $5 \mathrm{~min}$. The gel was given time to settle before decanting the aqueous layer. The excess water was then removed from the solid by vacuum filtration and further dried overnight at $363 \mathrm{~K}$ in an oven. The catalyst was then crushed into a fine powder and treated in flowing air, increasing the temperature from ambient to $723 \mathrm{~K}$ at a rate of $0.16 \mathrm{~K} \mathrm{~s}^{-1}$, holding the condition for $4 \mathrm{~h}$.

A sol-gel method was used to synthesise $\mathrm{Ce} / \mathrm{Mn}$ mixed oxide materials. $\mathrm{KMnO}_{4}$ was dissolved in deionised water. Maleic acid was added while continuously stirring the solution. Cerium nitrate hexahydrate $\mathrm{Ce}\left(\mathrm{NO}_{3}\right)_{3} \cdot 6 \mathrm{H}_{2} \mathrm{O}$ (Alfa Aesar) was added to the solution in concentrations which provided a Ce/Mn molar ratios from 0.025 to 0.25 . The solution was stirred for either 40 or $60 \mathrm{~min}$ before the subsequent gel was given time to settle. The top aqueous layer was then decanted off. The gel was then washed four times by adding deionised water and stirring for approximately $5 \mathrm{~min}$; allowing the gel to settle and decanting the aqueous layer between each wash. The excess water was then removed from the solid by vacuum filtration before it was dried overnight at $363 \mathrm{~K}$ in an oven. The catalyst was then crushed into powder and treated in flowing air, increasing the temperature from ambient to $723 \mathrm{~K}$ at a rate of $0.16 \mathrm{~K} \mathrm{~s}^{-1}$, holding the condition for $4 \mathrm{~h}$. The samples produced are denoted as $\mathrm{Ce}[\mathrm{X}]$ $\mathrm{Mn}$, where $\mathrm{X}$ is the $\mathrm{Ce} / \mathrm{Mn}$ molar ratio.

The same sol-gel method was used to synthesise $\mathrm{Ce} / \mathrm{Zr} /$ Mn mixed oxide materials. In this synthesis route, cerium zirconium oxide (Sigma Aldrich) with a $\mathrm{CeO}_{2} / \mathrm{ZrO}_{2}$ ratio of $1: 1$, was added to the solution of $\mathrm{KMnO}_{4}$ and maleic acid before stirring for either 40 or $60 \mathrm{~min}$. The concentration of cerium zirconium oxide added to the solution provided theoretical $\mathrm{Ce} / \mathrm{Zr} / \mathrm{Mn}$ molar ratios of 0.09/0.09/1 and $0.125 / 0.125 / 1$. Excess water was removed from the solid by vacuum filtration and dried overnight at $363 \mathrm{~K}$. The catalyst was crushed into a powder and treated in flowing air, increasing the temperature from ambient to $723 \mathrm{~K}$ at a rate of $0.16 \mathrm{~K} \mathrm{~s}^{-1}$, holding the condition for $4 \mathrm{~h}$. The subsequent samples were denoted as $\mathrm{Ce}[\mathrm{X}] \mathrm{Zr}[\mathrm{Y}]-\mathrm{Mn}: \mathrm{Z}$, where $\mathrm{X}$ and $\mathrm{Y}$ are the $\mathrm{Ce}$ and $\mathrm{Zr}$ mole ratios respectively and $\mathrm{Z}$ is the stirring time in minutes.

A sample of each $\mathrm{Ce} / \mathrm{Mn}$ and $\mathrm{Ce} / \mathrm{Zr} / \mathrm{Mn}$ catalysts were loaded with $1 \mathrm{wt} \% \mathrm{Pt}$ by incipient wetness impregnation using platinum nitrate solution (15 wt $\%$, Alfa Aesar), as a platinum precursor. After impregnation the materials were dried at $393 \mathrm{~K}$ for $4 \mathrm{~h}$ then calcined at $723 \mathrm{~K}$ for $4 \mathrm{~h}$.

\subsection{Material Characterisation}

Powder X-ray diffraction (XRD) analysis provided structural information on the studied catalysts, verifying their chemical composition and crystallinity. The data were collected using a PANanalytical X'Pert Pro X-ray diffractometer. A $\mathrm{Cu} \mathrm{K \alpha}$ radiation source was used with a wavelength of $1.5405 \AA$. All measurements were carried out ex-situ using a spinning stage. The data were recorded over a $2 \theta$ range from $15^{\circ}$ to $75^{\circ}$ with a step size of $0.017^{\circ}$. X'Pert HighScore Plus software was used to analyse the XRD patterns and crystallite sizes were estimated by using the Scherrer Calculator tool.

Brunauer-Emmett-Teller (BET) method was used to provide surface area values. $\mathrm{N}_{2}$ was used as the adsorptive. The surface area and pore volume were determined from the $\mathrm{N}_{2}$ adsorption-desorption isotherms at $77 \mathrm{~K}$ using a Micromeritics ASAP 2010. The samples were degassed at $393 \mathrm{~K}$, under vacuum, for $24 \mathrm{~h}$ carrying out before nitrogen adsorption studies.

Elemental wt\% compositions of $\mathrm{Ce}, \mathrm{Zr}, \mathrm{K}$ and $\mathrm{Mn}$ were determined by inductively coupled plasma optical emission spectrometry (ICP-OES) analysis using Perkin-Elmer 4300.

\subsection{Catalytic Testing}

Each sample was tested under conditions designed to replicate those occurring in the catalytic converter of a lean burning combustion engine. A quartz micro-reactor (with inner diameter of $0.6 \mathrm{~cm}$ and length of $30 \mathrm{~cm}$ ) containing $0.1 \mathrm{~g}$ of powder catalyst in a fixed bed was used. The reactor was positioned in a single zone tubular Carbolite furnace. A $\mathrm{K}$-type thermocouple positioned in the centre of the catalyst bed, was connected to a Eurotherm 3216 PID controller and used to control the temperature of the furnace, and hence, 
the reactor. Each reactant was fed to the reactor by individual Brooks thermal mass flow controllers, with a total flow rate of $16.7 \mathrm{~cm}^{3} \mathrm{~g}^{-1} \mathrm{~s}^{-1}$.

Light-off tests were carried out to determine the $\mathrm{CO}$ and $\mathrm{C}_{3} \mathrm{H}_{6}$ light-off temperatures achievable over each catalyst. The temperature was increased from 313 to $773 \mathrm{~K}$ at a rate of $0.083 \mathrm{~K} \mathrm{~s}^{-1}$ while flowing a reactant feed composed of $10 \% \mathrm{O}_{2}, 4.5 \% \mathrm{H}_{2} \mathrm{O}, 2000 \mathrm{ppm} \mathrm{CO}, \mathrm{CH}_{4}, \mathrm{C}_{3} \mathrm{H}_{6}, 200 \mathrm{ppm}$ $\mathrm{NO}$; the balance was made up with Ar. A Pfeiffer Vacuum OmniStar, quadrupole mass spectrometer was used to analyse the outlet gases. Three test cycles were carried out on each sample to ensure their stability and the reported lightoff curves are those obtained on the third cycle. The catalyst light-off temperatures were regarded as the temperature at which 50\% conversion was obtained and are henceforth referred to as $\mathrm{T}_{50}$ values.

\section{Results and Discussion}

\subsection{Effect of Ceria Incorporation}

The effect of introducing ceria into the synthesis method of K-OMS-2, to create an amorphous Ce/Mn mixed solid solution, was evaluated by varying the $\mathrm{Ce} / \mathrm{Mn}$ molar ratio of the catalysts prepared. The theoretical $\mathrm{Ce} / \mathrm{Mn}$ molar ratio used in the 60 min sol-gel synthesis method was increased from 0.025 to 0.25 . A comparative study was carried out on samples synthesised using the 40 min sol-gel method, using theoretical Ce/Mn ratios of 0.175 and 0.25 .

The morphology and structural properties of these catalysts using powder X-ray diffraction. The XRD patterns of the catalyst samples synthesised using the 60 min method are shown in Fig. 1. These reveal that increasing the $\mathrm{Ce}$ content of the materials, leads to the demise of the crystalline structure. OMS-2:60 expressed all of the phases characteristic of the tunnel structure of OMS-2; showing peaks at $2 \theta=18^{\circ}, 25.8^{\circ}, 28.7^{\circ}, 37.5^{\circ}, 42^{\circ}, 50^{\circ}, 56.5^{\circ}, 60.5^{\circ}$ and $65^{\circ}$ which correspond the (200), (220), (310), (211), (301), (411), (600), (521) and (002) facets respectively [35]. All of the $\mathrm{Ce} / \mathrm{Mn}$ samples proved to be amorphous with the exception of $\mathrm{Ce}$ [0.025]-Mn:60, which expressed the phases associated with OMS-2. It can be deduced that the when using the sol-gel method applied in this work, the crystalline structure characteristic of OMS-2 will form using a low $\mathrm{Ce} / \mathrm{Mn}$ ratio of 0.025 . However, increasing the $\mathrm{Ce} / \mathrm{Mn}$ ratio to 0.08 will prevent the formation of the crystalline phases. With the incorporation of larger $\mathrm{Ce}^{4+}$ into the OMS-2 framework, the formation of nano-needles is hindered due to the reduced concentration of smaller $\mathrm{Mn}^{4+}$ cations, preventing the structure from forming $[8,16,35]$. This may indicate that the $\mathrm{Ce}$ is incorporated into the material's framework using the sol-gel synthesis method, rather than being positioned

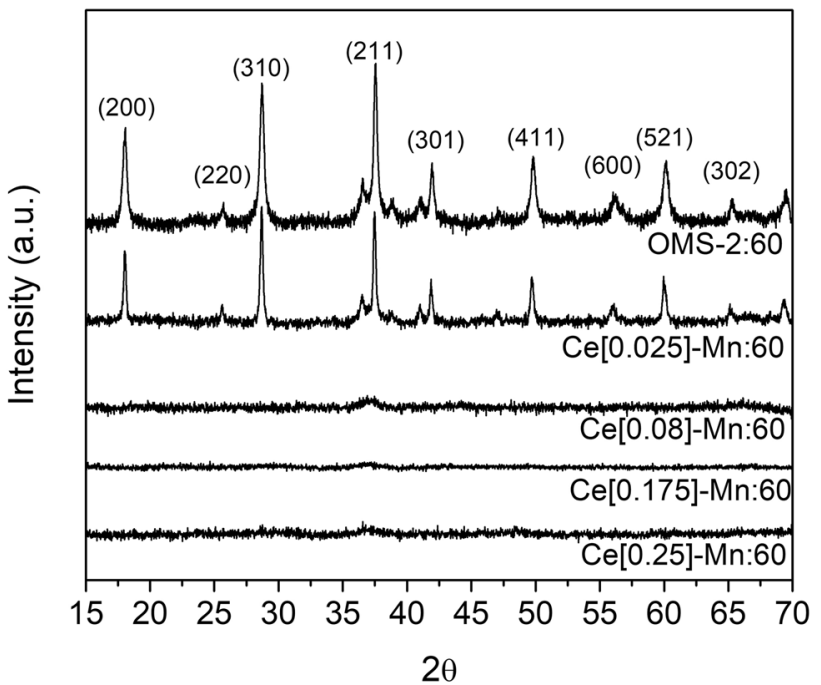

Fig. 1 XRD patterns of Ce/Mn catalysts compared with OMS-2:60

around it or within the 'tunnel' structure. This explains the reduced crystallinity observed when a small concentration of Ce was incorporated in Ce[0.025]-Mn. It may suggest that Ce has been substituted for Mn in the OMS-2 lattice, however, an amorphous phase $\mathrm{Ce} / \mathrm{Mn}$ mixed oxide phase may also be present. As the Ce/Mn mole ratio increases above 0.08 , the higher concentration of Ce prevents any formation of the crystalline tunnel structure of OMS-2, and the resulting materials are considered to be amorphous $\mathrm{Ce} / \mathrm{Mn}$ mixed oxides. To fully understand the structures and atomic environments of the catalysts would require more in-depth characterisation such as XAFS or TEM-EDX analysis. SEM images revealed that Ce[0.025]-Mn:60 still contains a small quantity of well defined, nano-needles. Peaks characteristic to a $\mathrm{CeO}_{2}$ are absent from the XRD pattern of $\mathrm{Ce}[0.025]-$ $\mathrm{Mn}: 60$, suggesting that cerium is present in the form of cations, positioned inside the tunnel structure of OMS, rather than a free ceria phase. A similar effect was revealed through XRD analysis of the 40 min samples, as reported in Figure S1 of the supporting document.

Structural information on each sample was obtained through BET analysis and are reported in Table 1. It was found that the addition of Ce alone in the sol-gel method increases the surface area of the subsequent material. The surface areas of $\mathrm{Ce}[0.175]-\mathrm{Mn}: 60$ and $\mathrm{Ce}[0.25]-\mathrm{Mn}: 60$ were $225.1 \mathrm{~m}^{2} \mathrm{~g}^{-1}$ and $337 \mathrm{~m}^{2} \mathrm{~g}^{-1}$ respectively. This shows an increase of surface area by a factor of more than 2 between $\mathrm{Ce}[0.25]-\mathrm{Mn}: 60$ and OMS-2:60, which had a surface area of $124.6 \mathrm{~m}^{2} \mathrm{~g}^{-1}$. A similar effect can be noted between samples synthesised with a stirring time of $40 \mathrm{~min}$. OMS-2:40, $\mathrm{Ce}[0.175]-\mathrm{Mn}: 40$ and Ce[0.25]-Mn:40 had surface areas of $126.8 \mathrm{~m}^{2} \mathrm{~g}^{-1} 207.1 \mathrm{~m}^{2} \mathrm{~g}^{-1}$ and $198.9 \mathrm{~m}^{2} \mathrm{~g}^{-1}$ respectively; however, the latter two showed similar surface areas. 
Table 1 BET surface area $\left(\mathrm{m}^{2}\right.$ $\left.\mathrm{g}^{-1}\right)$ and pore volume $\left(\mathrm{cm}^{3} \mathrm{~g}^{-1}\right)$ of all synthesised OMS-2, Ce/ $\mathrm{Mn}$ and $\mathrm{Ce} / \mathrm{Zr} / \mathrm{Mn}$

\begin{tabular}{|c|c|c|c|c|c|c|c|}
\hline \multirow[t]{2}{*}{ Material } & \multirow{2}{*}{$\begin{array}{l}\text { Surface area } \\
\left(\mathrm{m}^{2} \mathrm{~g}^{-1}\right)\end{array}$} & \multirow{2}{*}{$\begin{array}{l}\text { Pore volume } \\
\left(\mathrm{cm}^{3} \mathrm{~g}^{-1}\right)\end{array}$} & \multicolumn{5}{|c|}{ ICP-OES } \\
\hline & & & $\mathrm{Ce}$ & $\mathrm{Zr}$ & Mn & $\mathrm{K}$ & $\mathrm{Pt}$ \\
\hline OMS-2:60 & 124.6 & 0.203 & - & - & 71.7 & 7.9 & - \\
\hline OMS-2:40 & 126.8 & 0.203 & - & - & 61.3 & 8.8 & - \\
\hline $\mathrm{Ce}[0.025]-\mathrm{Mn}: 60$ & 177.5 & 0.232 & 5 & - & 58.1 & 8 & - \\
\hline $\mathrm{Ce}[0.08]-\mathrm{Mn}: 60$ & 275.2 & 0.302 & 10.3 & - & 49.6 & 8.8 & - \\
\hline $\mathrm{Ce}[0.175]-\mathrm{Mn}: 60$ & 225.1 & 0.358 & 20.8 & - & 48.9 & 4.7 & - \\
\hline $\mathrm{Ce}[0.175]-\mathrm{Mn}: 40$ & 207.1 & 0.312 & 20.1 & - & 45.3 & 4.9 & - \\
\hline $\mathrm{Ce}[0.25]-\mathrm{Mn}: 60$ & 337.1 & 0.497 & 25.3 & - & 37.9 & 3.3 & - \\
\hline $\mathrm{Ce}[0.25]-\mathrm{Mn}: 40$ & 198.9 & 0.41 & 27.4 & - & 42 & 3.1 & - \\
\hline $\mathrm{Ce}[0.09] \mathrm{Zr}[0.09]-\mathrm{Mn}: 60$ & 62.9 & 0.213 & 11.1 & 5 & 43.7 & 6.4 & - \\
\hline $\mathrm{Ce}[0.09] \mathrm{Zr}[0.09]-\mathrm{Mn}: 40$ & 122.5 & 0.237 & 20 & 13 & 39.1 & 3.5 & - \\
\hline $\mathrm{Ce}[0.125] \mathrm{Zr}[0.125]-\mathrm{Mn}: 60$ & 107.9 & 0.209 & 13.3 & 9.6 & 33 & 5.7 & - \\
\hline $\mathrm{Ce}[0.125] \mathrm{Zr}[0.125]-\mathrm{Mn}: 40$ & 127.5 & 0.202 & 25.4 & 16.5 & 33.9 & 3 & - \\
\hline $\mathrm{Ce}[0.5] \mathrm{Zr}[0.5]$ & 9.8 & 0.04 & 47.5 & 30.8 & - & - & - \\
\hline Pt:Ce[0.25]-Mn:40 & 233.3 & 0.336 & 27.8 & - & 42.2 & 2.9 & 0.9 \\
\hline Pt:Ce[0.09]Zr[0.09]-Mn:40 & 106.5 & 0.175 & 10.6 & 3.5 & 35.6 & 5.7 & 0.7 \\
\hline $\mathrm{Pt}: \mathrm{Ce}[0.5] \mathrm{Zr}[0.5]$ & 88.2 & 0.193 & 47 & 30.5 & - & - & 1 \\
\hline
\end{tabular}

The catalytic activity of each sample was assessed and compared with pure OMS-2:60. CO light-off curves are reported in Fig. $2 \mathrm{a}$ and $\mathrm{C}_{3} \mathrm{H}_{6}$ light-off curves are shown in Fig. 2b. From Fig. 2a it can be observed that the addition of ceria to the manganese catalysts gave a reduction of the $\mathrm{CO}$ $\mathrm{T}_{50}$ value. Figure $2 \mathrm{a}$ shows that the CO light-off temperature decreases as the $\mathrm{Ce} / \mathrm{Mn}$ ratio increases. The trend of $\mathrm{CO} \mathrm{T}{ }_{50} ; \mathrm{Ce}[0.25]-\mathrm{Mn}: 60<\mathrm{Ce}[0.175]-\mathrm{Mn}: 60<\mathrm{Ce}[0.08]-$ $\mathrm{Mn}: 60 \leq \mathrm{Ce}[0.025]-\mathrm{Mn}: 60<\mathrm{OMS}-2: 60$. This proved a decrement in $\mathrm{CO} \mathrm{T}_{50}$ of around $70 \mathrm{~K}$ was achieved over $\mathrm{Ce}[0.25]-\mathrm{Mn}: 60$, compared to OMS-60. A similar trend was observed in the $\mathrm{C}_{3} \mathrm{H}_{6}$ light-off curves in Fig. $2 \mathrm{~b}$ which shows that the $\mathrm{C}_{3} \mathrm{H}_{6}$ light-off temperature decreased by $37 \mathrm{~K}$ between OMS-2:60 and Ce[0.25]-Mn:60. However, it can be noted that $\mathrm{Ce}[0.175]-\mathrm{Mn}: 60$ and $\mathrm{Ce}[0.25]-\mathrm{Mn}: 60$ provided similar $\mathrm{C}_{3} \mathrm{H}_{6} \mathrm{~T}_{50}$ values. Despite having a lower surface area of $124.6 \mathrm{~m}^{2} \mathrm{~g}^{-1}$, OMS-2:60 showed a similar $\mathrm{C}_{3} \mathrm{H}_{6} \mathrm{~T}_{50}$ values to that of $\mathrm{Ce}[0.025]-\mathrm{Mn}: 60$, which had a surface area of $177.5 \mathrm{~m}^{2} \mathrm{~g}^{-1}$. However, it can also be seen that OMS-2:60 gave a faster reaction rate and achieved $\mathrm{C}_{3} \mathrm{H}_{6} \mathrm{~T}_{90}$ at $575 \mathrm{~K}$, which was around $45 \mathrm{~K}$ lower than the $\mathrm{C}_{3} \mathrm{H}_{6} \mathrm{~T}_{90}$ over $\mathrm{Ce}[0.025]-\mathrm{Mn}: 60$. The catalytic activity of $\mathrm{Ce}[0.025]-\mathrm{Mn}: 60$ in $\mathrm{C}_{3} \mathrm{H}_{6}$ oxidation can also be compared with previously reported results for Benzene oxidation. Liu and Hou [26] reported that a material with a similar composition to Ce[0.025]-Mn:60 gave a similar $\mathrm{T}_{50}$ value than the corresponding OMS-2 catalyst. However, the OMS-2 catalyst in their study gave a faster rate of reaction and achieved lower $\mathrm{T}_{90}$ value than the sample doped with Ce.

It was observed from a previous study, that the stirring time of the precursor during the material synthesis, has an
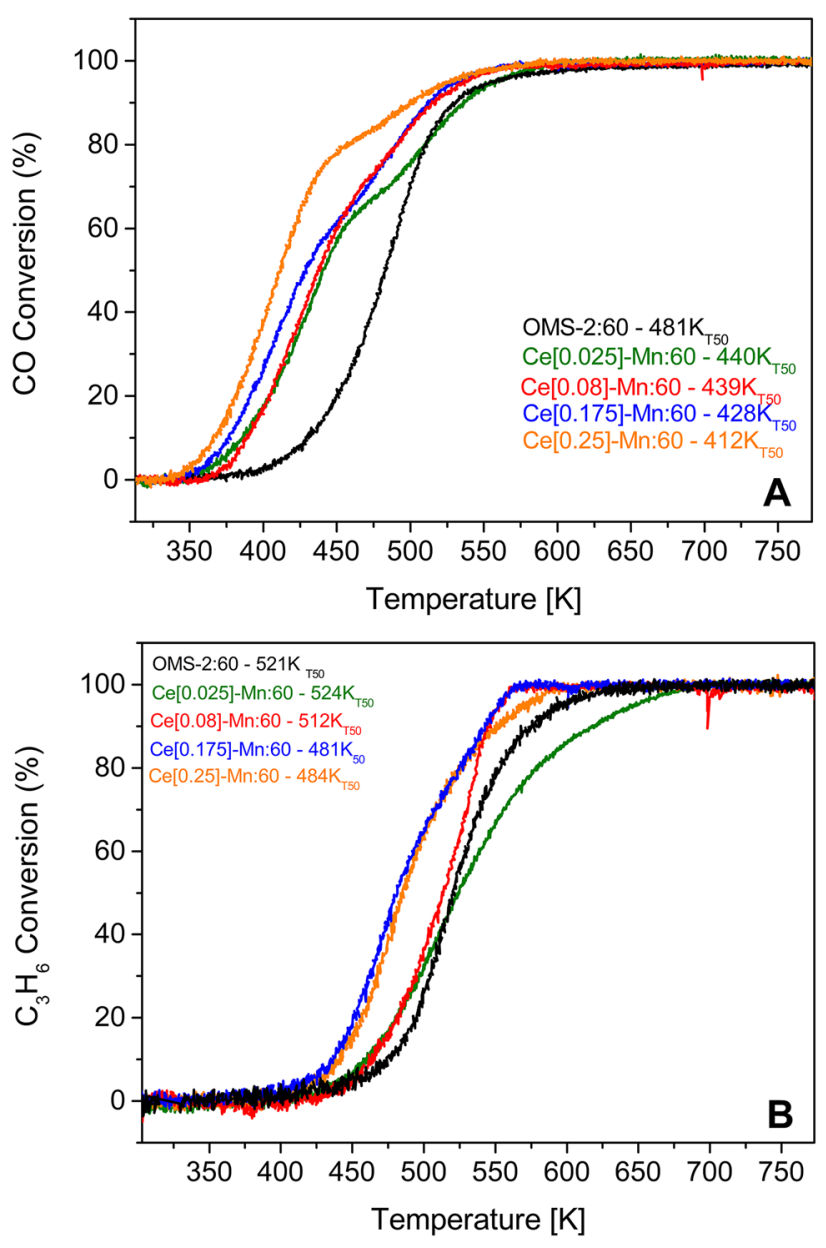

Fig. 2 Comparison of $\mathrm{CO}$ conversion (a) and $\mathrm{C}_{3} \mathrm{H}_{6}$ conversion (b) obtained over OMS-2:60 and Ce/Mn samples synthesised for $60 \mathrm{~min}$, compared with $\mathrm{CeO}_{2}$ 
effect on the subsequent catalyst. It was found that reducing the stirring time of the precursor from 60 to $40 \mathrm{~min}$, had no effect on the catalytic performance of the end material. As discussed in the previous paragraph, catalysts synthesised using $\mathrm{Ce} / \mathrm{Mn}$ ratios of 0.175 and 0.25 , and a stirring time of 60 min, gave the lowest $\mathrm{CO}$ and $\mathrm{C}_{3} \mathrm{H}_{6}$ light-off temperatures (Fig. 2). Therefore, a similar study has been carried out by synthesising $\mathrm{Ce} / \mathrm{Mn}$ catalysts using a stirring time of the precursor of $40 \mathrm{~min}$ and $\mathrm{Ce} / \mathrm{Mn}$ ratios of 0.175 and 0.25 . The $40 \mathrm{~min} \mathrm{Ce} / \mathrm{Mn}$ samples were then compared with an OMS-2 which had also been synthesised using a stirring time of $40 \mathrm{~min}$.

The catalytic performance of the $40 \mathrm{~min} \mathrm{Ce} / \mathrm{Mn}$ samples were tested using the same light-off testing procedure as was used on the $60 \mathrm{~min} \mathrm{Ce} / \mathrm{Mn}$ samples. Figure 3 shows the $\mathrm{CO}$ and $\mathrm{C}_{3} \mathrm{H}_{6}$ light-off curves, obtained over the catalysts synthesised using a 40 min stirring time; $\mathrm{Ce}[0.175]$ $\mathrm{Mn}: 40, \mathrm{Ce}[0.25]-\mathrm{Mn}: 40$ and OMS-2:40. CO light-off curves are reported in Fig. 3a, which shows that as the Ce content of the materials increases, the $\mathrm{T}_{50}$ values for CO light-off decreases. A reduction in CO light-off of $50 \mathrm{~K}$ was achieved between OMS-2:40 and Ce[0.25]-Mn:40, which had CO $\mathrm{T}_{50}$ values of $477 \mathrm{~K}$ and $427 \mathrm{~K}$ respectively. The same trend is observed in Fig. $3 \mathrm{~b}$ for $\mathrm{C}_{3} \mathrm{H}_{6}$ light-off temperatures as seen in Fig. 3a for $\mathrm{CO}$ oxidation, whereby increasing the $\mathrm{Ce}$ content of the samples also resulted in a decrease of $\mathrm{C}_{3} \mathrm{H}_{6}$ light-off. A reduction of around $50 \mathrm{~K}$ was achieved over $\mathrm{Ce}[0.25]-\mathrm{Mn}: 40$ compared with OMS-2:40, which gave $\mathrm{C}_{3} \mathrm{H}_{6} \mathrm{~T}_{50}$ values of $479 \mathrm{~K}$ and $531 \mathrm{~K}$ respectively.

A comparable study on a commercial sample of $\mathrm{CeO}_{2}$ (Sigma Aldrich), was carried out within our research group. The $\mathrm{CeO}_{2}$ sample was tested using the same method as previously mentioned and the $\mathrm{CO}$ and $\mathrm{C}_{3} \mathrm{H}_{6}$ light-off curves from this experiment is reported in Fig. $\mathrm{S} 3$ of the supporting information. Figure $\mathrm{S} 3$ reports that the $\mathrm{CO}$ and $\mathrm{C}_{3} \mathrm{H}_{6} \mathrm{~T}_{50}$ values over pure $\mathrm{CeO}_{2}$ were $576 \mathrm{~K}$ and $645 \mathrm{~K}$ respectively. When comparing these light-off values with those obtained over the manganese based catalysts synthesised in this work, we realise that the $\mathrm{CO}$ and $\mathrm{C}_{3} \mathrm{H}_{6} \mathrm{~T}_{50}$ values are remarkably lower. Figure 2 reported $\mathrm{CO}$ and $\mathrm{C}_{3} \mathrm{H}_{6} \mathrm{~T}_{50}$ values of $412 \mathrm{~K}$ and $484 \mathrm{~K}$ (respectively) over $\mathrm{Ce}[0.25]-\mathrm{Mn}: 60$. These values show that $\mathrm{CO}$ and $\mathrm{C}_{3} \mathrm{H}_{6}$ light-off temperatures were decreased by up to $164 \mathrm{~K}$ and $161 \mathrm{~K}$ (respectively) through the incorporation of ceria in manganese, compared to pure $\mathrm{CeO}_{2}$. A similar result is noticed over $\mathrm{Ce}[0.25]-\mathrm{Mn}: 40$ in Fig. 3, which reported corresponding $\mathrm{CO}$ and $\mathrm{C}_{3} \mathrm{H}_{6} \mathrm{~T}_{50}$ values of $427 \mathrm{~K}$ and $479 \mathrm{~K}$. These values showed that the $\mathrm{CO}$ and $\mathrm{C}_{3} \mathrm{H}_{6}$ light-off temperatures decreased by $149 \mathrm{~K}$ and $166 \mathrm{~K}$ respectively, compared with $\mathrm{CeO}_{2}$.

A study carried out by Jan et al. [19] reported CO lightoff at approximately $543 \mathrm{~K}$, over a $\mathrm{Pt}(0.5$ atomic $\%) \mathrm{CeO}_{2}$ catalyst prepared by co-precipitation method. Another study carried out by Bera et al. [5] also reported CO light-off at
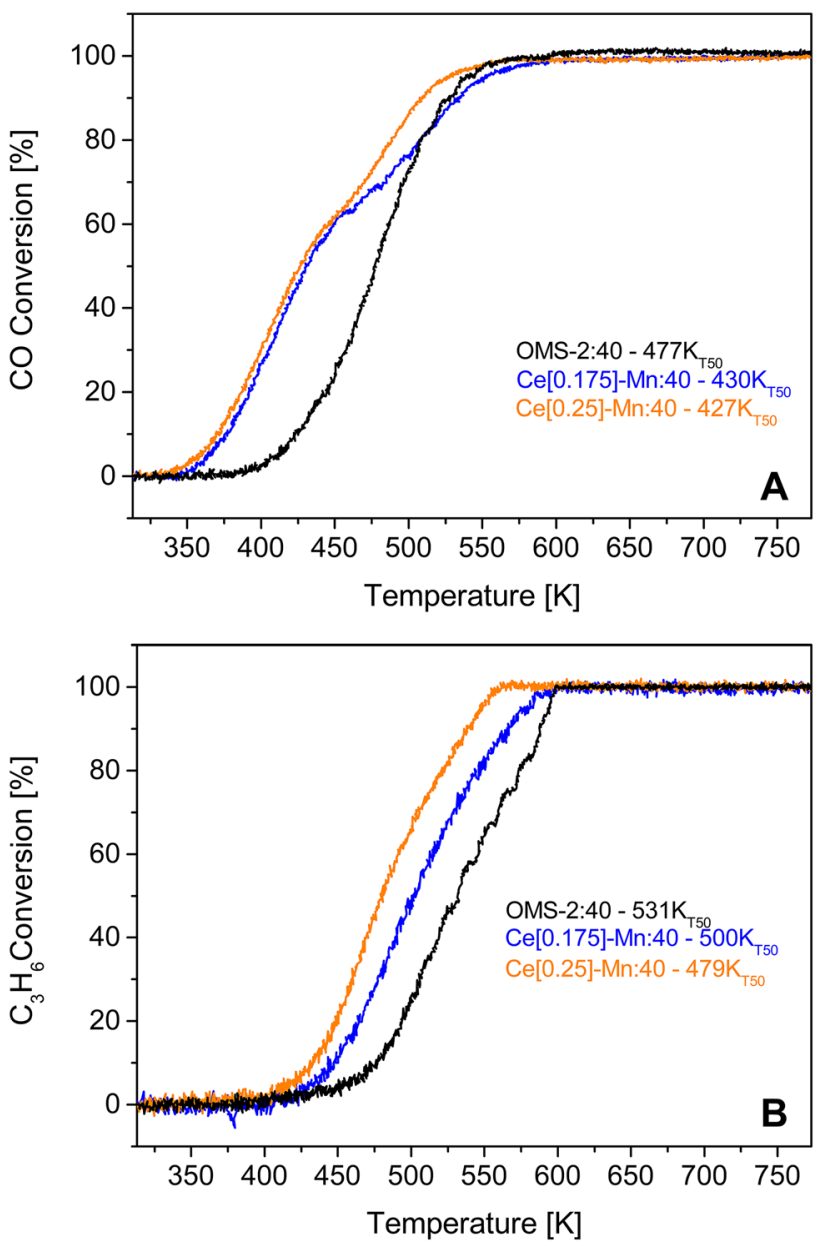

Fig. 3 Comparison of $\mathrm{CO}$ conversion (a) and $\mathrm{C}_{3} \mathrm{H}_{6}$ conversion (b) obtained over OMS-2:40 and Ce/Mn samples synthesised for $40 \mathrm{~min}$, compared with $\mathrm{CeO}_{2}$

around $453 \mathrm{~K}$, over a $1 \mathrm{wt} \% \mathrm{Pt} \mathrm{CeO}_{2}$ catalyst prepared using a solution combustion method. Both of these studies reported CO light-off temperatures that were higher than the $\mathrm{Ce} / \mathrm{Mn}$ based catalysts, which had no noble metal loading, prepared in this work.

During the synthesis of Ce[0.5]-Mn:60, Ce[0.5]-Mn:40, the precursor solutions were stirred for $60 \mathrm{~min}$ and $40 \mathrm{~min}$ respectively, using the same $\mathrm{Ce} / \mathrm{Mn}$ ratio of 0.5 . The samples prepared using the same $\mathrm{Ce} / \mathrm{Mn}$ mole ratio and stirring times of 60 and $40 \mathrm{~min}$, show a similar decrease in the $\mathrm{T}_{50}$ value for $\mathrm{CO}$ (Figs. 2 and 3 ) compared to the corresponding OMS-2 catalysts (OMS-2:60 and OMS-2:40). This can be directly correlated to the increase of the surface areas of these samples which were $225.1 \mathrm{~m}^{2} \mathrm{~g}^{-1}$ and $207.1 \mathrm{~m}^{2} \mathrm{~g}^{-1}$ for $\mathrm{Ce}[0.175]-\mathrm{Mn}: 60$ and $\mathrm{Ce}[0.175]-\mathrm{Mn}: 40$ respectively. Moreover, The $\mathrm{CO} \mathrm{T}_{50}$ observed over Ce[0.25]-Mn:60 was $412 \mathrm{~K}$, which was $15 \mathrm{~K}$ lower than that of $\mathrm{Ce}[0.25]-\mathrm{Mn}: 40$. This difference in CO light-off temperature can be attribute 
to the surface area of these samples. Ce[0.25]-Mn:60 which was prepared using a stirring time of $60 \mathrm{~min}$ and a Ce/Mn mole ratio of 0.25 , had a surface area of $337.1 \mathrm{~m}^{2} \mathrm{~g}^{-1}$. This value is around $60 \%$ higher than the correspondent sample synthesised using a stirring time of $40 \mathrm{~min}, \mathrm{Ce}[0.25]-\mathrm{Mn}: 40$, which had a surface area of $198.9 \mathrm{~m}^{2} \mathrm{~g}^{-1}$ This is in line with literature results that report a direct dependence of the $\mathrm{CO}$ light-off temperature to the surface area of the catalyst [25]. This can be explained by the increased number of oxygen vacancies and improved oxygen mobility through the catalyst structure.

In comparison, the same trend of the decrement of the $\mathrm{T}_{50}$ value by increasing the surface area is not observed in $\mathrm{C}_{3} \mathrm{H}_{6}$ oxidation values. $\mathrm{Ce}[0.175]-\mathrm{Mn}: 60$ gave a $\mathrm{C}_{3} \mathrm{H}_{6} \mathrm{~T}_{50}$ value which was $20 \mathrm{~K}$ less than the sample prepared with the same $\mathrm{Ce} / \mathrm{Mn}$ mole ratio, using a stirring time of $40 \mathrm{~min}$. This can be explained with the fact that $\mathrm{HC}$ oxidation is more strongly related to the catalyst structure and the presence of $\mathrm{Mn}^{4+}-\mathrm{O}^{2-}$ type Lewis acid-base pairs, rather than the surface area $[14,35]$.

From Figs. 2a and 3a, it can also be noted that CO lightoff curves of the $\mathrm{Ce} / \mathrm{Mn}$ catalysts display a shoulder in the conversion profile, due to a slight decrease in the reaction rate within the temperature range of $450 \mathrm{~K}$ and $500 \mathrm{~K}$. This can be attributed to the competitive adsorption between $\mathrm{CO}$ and hydrocarbons; particularly as intermediate species are formed on the surface during $\mathrm{C}_{3} \mathrm{H}_{6}$ oxidation in the presence of NOx [7, 10]. This shoulder is not observed in the CO light-off curves of OMS-2:60 (Fig. 2a) and OMS-2:40 (Fig. 3a).

The incorporation of $\mathrm{Ce}$ in manganese oxide affected the rate of $\mathrm{CO}$ oxidation that became slower compared to the one observed on the pure manganese oxide. The rate of $\mathrm{C}_{3} \mathrm{H}_{6}$ doesn't show a significant variation with the presence of $\mathrm{Ce}$. For this reason, two-step oxidation of $\mathrm{CO}$ is less pronounced for high $\mathrm{Ce} / \mathrm{Mn}$ ratios [35].

\subsection{Effect of Ceria Zirconia Incorporation}

The effect of introducing ceria zirconia into the synthesis method of K-OMS-2, to create a Ce/Zr/Mn mixed solid solution, was evaluated by varying the $\mathrm{Ce} / \mathrm{Zr} / \mathrm{Mn}$ molar ratio of the catalysts prepared. The samples were prepared with same $\mathrm{Ce} / \mathrm{Mn}$ and $\mathrm{Zr} / \mathrm{Mn}$ mole ratios of 0.09 and 0.125 , using stirring times of $60 \mathrm{~min} 40 \mathrm{~min}$.

Each sample was characterised by BET surface area analysis (Table 1) and powder X-ray diffraction studies. The XRD diffractograms of the 40 min samples prepared with $\mathrm{Ce} / \mathrm{Zr} / \mathrm{Mn}$ ratios of 0.09 and 0.125 are displayed in Fig. 4, together with OMS-2:40 and a commercial sample of $\mathrm{Ce}[0.5] \mathrm{Zr}[0.5]$. Figure 4 shows that $\mathrm{Ce}[0.09] \mathrm{Zr}[0.09]-\mathrm{Mn}: 40$ has crystalline phases characteristic of OMS: 40 at $2 \theta=18^{\circ}$, $25.8^{\circ}, 28.7^{\circ}, 37.5^{\circ}, 42^{\circ}, 50^{\circ}, 56.5^{\circ}$ and $60.5^{\circ}$ and $\mathrm{Ce}[0.5]$
$\operatorname{Zr}[0.5]$ at $2 \theta=29.5^{\circ}, 33.8^{\circ}, 49.1^{\circ}, 58.5^{\circ}$ and $61.5^{\circ}$, indicating two crystalline phases contributing to the materials structure; an OMS-2 phase and a $\mathrm{Ce}[0.5] \mathrm{Zr}[0.5]$ phase. The XRD pattern of $\mathrm{Ce}[0.125] \mathrm{Zr}[0.125]-\mathrm{Mn}: 40$ shows peaks at $2 \theta=33.6^{\circ}, 49.3^{\circ}, 57^{\circ}$ and $59.6^{\circ}$, which can be ascribed to the presence of a $\mathrm{Ce}[0.5] \mathrm{Zr}[0.5]$ phase. The Mn phase is not evident from the XRD pattern but Mn presence was verified through ICP-OES analysis. The XRD pattern of Ce[0.09] $\mathrm{Zr}[0.09]-\mathrm{Mn}: 40$ shows a peak at $2 \theta=37.6^{\circ}$, which can be related to the presence of the (211) facet of manganese oxide as is present in OMS-2:40. This peak became less intense as the $\mathrm{Ce} / \mathrm{Mn}$ ratio was increased to 0.125 . The same trend is followed by the other peak observed at $2 \theta=29^{\circ}$, which can be attributed to a crystalline phases of either $\mathrm{Ce}[0.5]$ $\mathrm{Zr}[0.5]$ or OMS-2. It is observed that at high mole ratios of $\mathrm{Ce} / \mathrm{Zr} / \mathrm{Mn}$ prevents the formation of the tunnel structure of OMS-2, and an amorphous Mn phase is formed along with a crystalline $\mathrm{Ce}[0.5] \mathrm{Zr}[0.5]$ phase. This is a similar effect seen in the synthesis of the $\mathrm{Ce} / \mathrm{Mn}$ materials previously reported in Fig. 1. The Scherrer equation was applied to the most intense peak of the $\mathrm{Ce}[0.5] \mathrm{Zr}[0.5]$ phase at $2 \theta=29.5^{\circ}$ to estimate the crystal sizes. There was no significant change in dimensions of the crystals in $\mathrm{Ce}[0.5] \mathrm{Zr}[0.5](\approx 16 \mathrm{~nm})$, $\mathrm{Ce}[0.09] \mathrm{Zr}[0.09]-\mathrm{Mn}: 40(\approx 18 \mathrm{~nm})$ and $\mathrm{Ce}[0.125] \mathrm{Zr}[0.125]-$ $\mathrm{Mn}: 40(\approx 19 \mathrm{~nm})$. Similar effects were observed in the XRD patterns of the samples synthesised using a stirring time of $60 \mathrm{~min}$ and the results are reported in Figure S2 of the supplementary information.

BET surface area analysis were also carried out on the $\mathrm{Ce} / \mathrm{Zr} / \mathrm{Mn}$ samples and the results of the surface area and

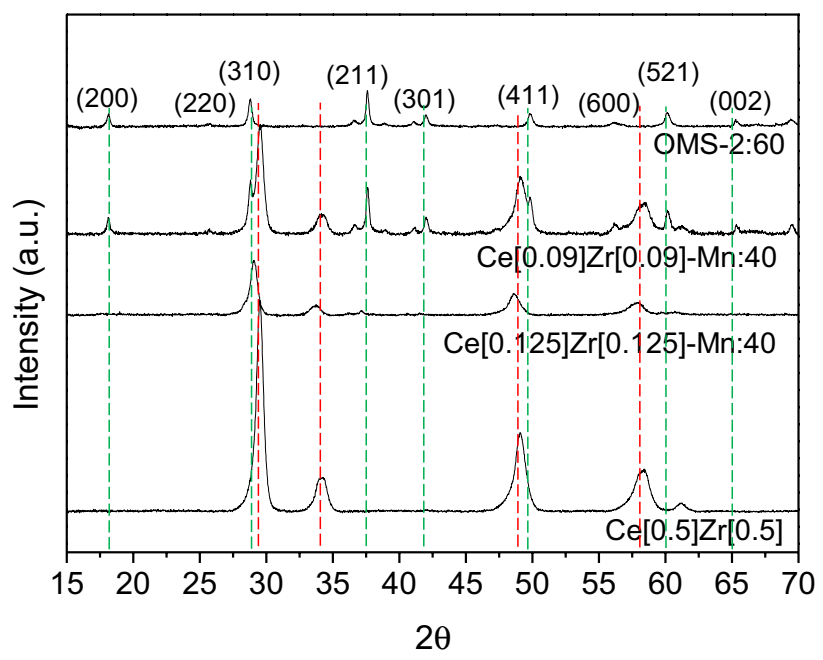

Fig. 4 XRD patterns of $\mathrm{Ce} / \mathrm{Zr} / \mathrm{Mn}$ synthesis using the $40 \mathrm{~min}$ sol-gel method, compared against reference samples of OMS-2:40 (top) and commercial $\mathrm{Ce}_{0.5} \mathrm{Zr}_{0.5} \mathrm{O}_{2}$ (bottom). Characteristic peaks of OMS-2 which are present in $\mathrm{Ce} / \mathrm{Zr} / \mathrm{Mn}$ samples are indicated by the vertical green line, while characteristic peaks of $\mathrm{Ce}_{0.5} \mathrm{Zr}_{0.5} \mathrm{O}_{2}$ are indicated by the vertical red lines 
pore volume are reported in Table 1 . It is observed in the results that the incorporation of $\mathrm{Ce}_{0.5} \mathrm{Zr}_{0.5} \mathrm{O}_{2}$ in the sol-gel method, resulted in a decrement of the surface area of the samples synthesised with 60 min stirring time. The surface area decreased from $124.6 \mathrm{~m}^{2} \mathrm{~g}^{-1}$ measured for OMS-2:60 to $62.9 \mathrm{~m}^{2} \mathrm{~g}^{-1}$ for $\mathrm{Ce}[0.09] \mathrm{Zr}[0.09]-\mathrm{Mn}: 60$. The incorporation of $\mathrm{Ce}_{0.5} \mathrm{Zr}_{0.5} \mathrm{O}_{2}$ in the sol-gel synthesis, had no notable effect on the surface area of the samples prepared using a stirring time of $40 \mathrm{~min}$ which showed a surface area of around $125 \mathrm{~m}^{2} \mathrm{~g}^{-1}$.

Light-off tests (as described in Sect. 2.3) were carried out on the $\mathrm{Ce} / \mathrm{Zr} / \mathrm{Mn}$ catalysts synthesised using a stirring time of $60 \mathrm{~min}$ and the results are reported in Fig. 5. Figure $5 \mathrm{a}$ reports the $\mathrm{CO}$ oxidation results for the $\mathrm{Ce} / \mathrm{Zr} / \mathrm{Mn}$ mixed oxide catalysts with a $\mathrm{Ce} / \mathrm{Mn}$ ratio ranging from 0.09 to 0.125 . The results are compared with those measured on manganese oxide synthesised using the same stirring time of $60 \mathrm{~min}$, and a commercially prepared sample of $\mathrm{Ce}_{0.5} \mathrm{Zr}_{0.5} \mathrm{O}_{2}$. Figure 5a shows that the $\mathrm{CO} \mathrm{T}_{50}$ values of $\mathrm{Ce}[0.125]$ $\mathrm{Zr}[0.125]-\mathrm{Mn}: 60$ (559 K), Ce[0.09]Zr[0.09]-Mn:60 (570 K)
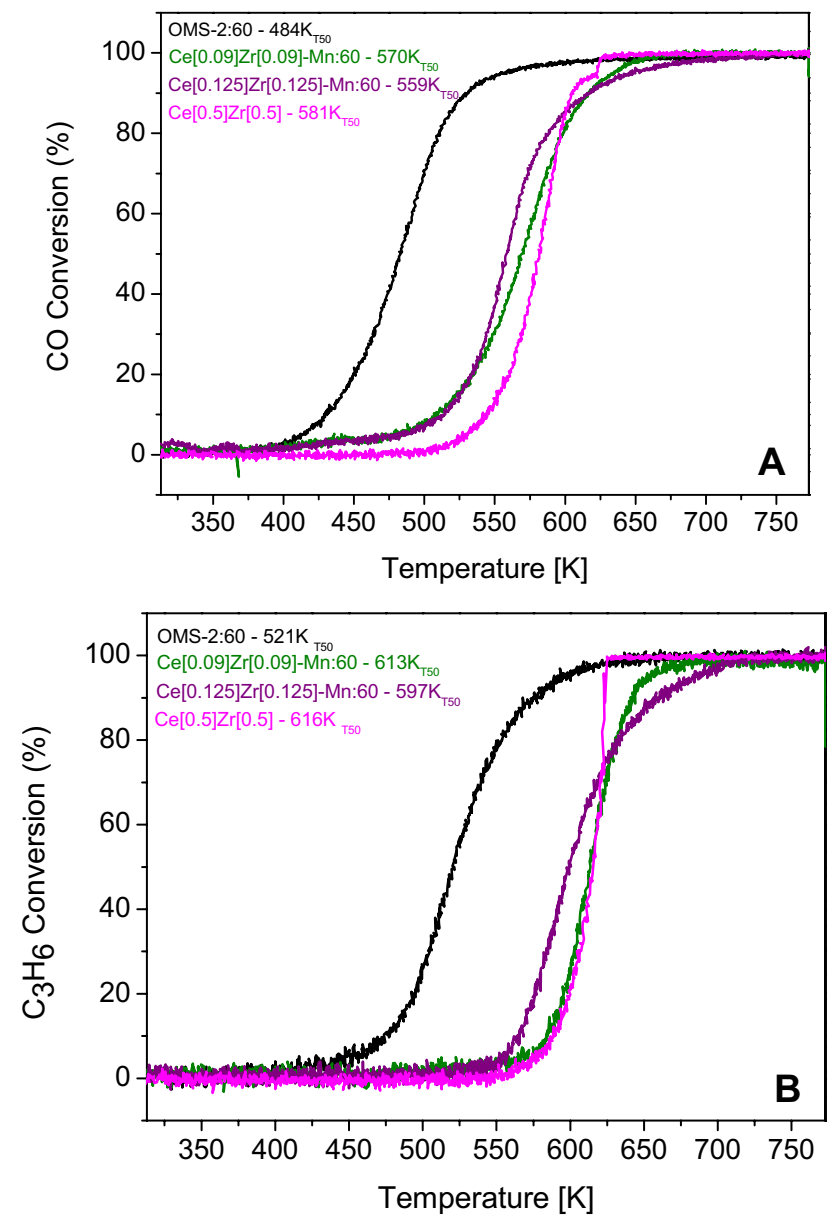

Fig. 5 Comparison of $\mathrm{CO}$ conversion (a) and $\mathrm{C}_{3} \mathrm{H}_{6}$ conversion (b) obtained over OMS-2:60 and $\mathrm{Ce} / \mathrm{Zr} / \mathrm{Mn}$ samples synthesised for $60 \mathrm{~min}$ are higher than that of the corresponding OMS-2:60 sample (484 K). However, the newly synthesised catalysts brought a reduction in $\mathrm{CO} \mathrm{T}_{50}$ of around $20 \mathrm{~K}$ compared to $\mathrm{Ce}[0.5]$ $\mathrm{Zr}[0.5]$. From Fig. $5 \mathrm{~b}$ it can be noted that the incorporation of $\mathrm{Ce}[0.5] \mathrm{Zr}[0.5]$ to manganese oxide had a negative effect also on $\mathrm{C}_{3} \mathrm{H}_{6}$ light-off temperature, with an increase of $76 \mathrm{~K}$ between $\mathrm{Ce}[0.125] \mathrm{Zr}[0.125]-\mathrm{Mn}: 60$ and OMS-2:60.

The $\mathrm{Ce} / \mathrm{Zr} / \mathrm{Mn}$ catalysts synthesised using a stirring time of $40 \mathrm{~min}$, were assessed using the same light-off testing procedure as previously described. The $\mathrm{CO}$ and $\mathrm{C}_{3} \mathrm{H}_{6}$ lightoff curves obtained from these tests are reported in Fig. 6 along with the corresponding OMS-2 sample and commercially prepared $\mathrm{Ce}[0.5] \mathrm{Zr}[0.5]$ sample. Figure 6 a reports the results attained from the $\mathrm{CO}$ oxidation over the newly synthesised $\mathrm{Ce} / \mathrm{Zr} / \mathrm{Mn}$ samples along with the corresponding manganese oxide and commercial $\mathrm{Ce}[0.5] \mathrm{Zr}[0.5]$ materials. The $\mathrm{C}_{3} \mathrm{H}_{6}$ conversion curves are reported in Fig. $6 \mathrm{~b}$ for the same samples. As observed for a stirring time of $60 \mathrm{~min}$, the addition of $\mathrm{Ce} / \mathrm{Zr}$ to manganese oxide has had
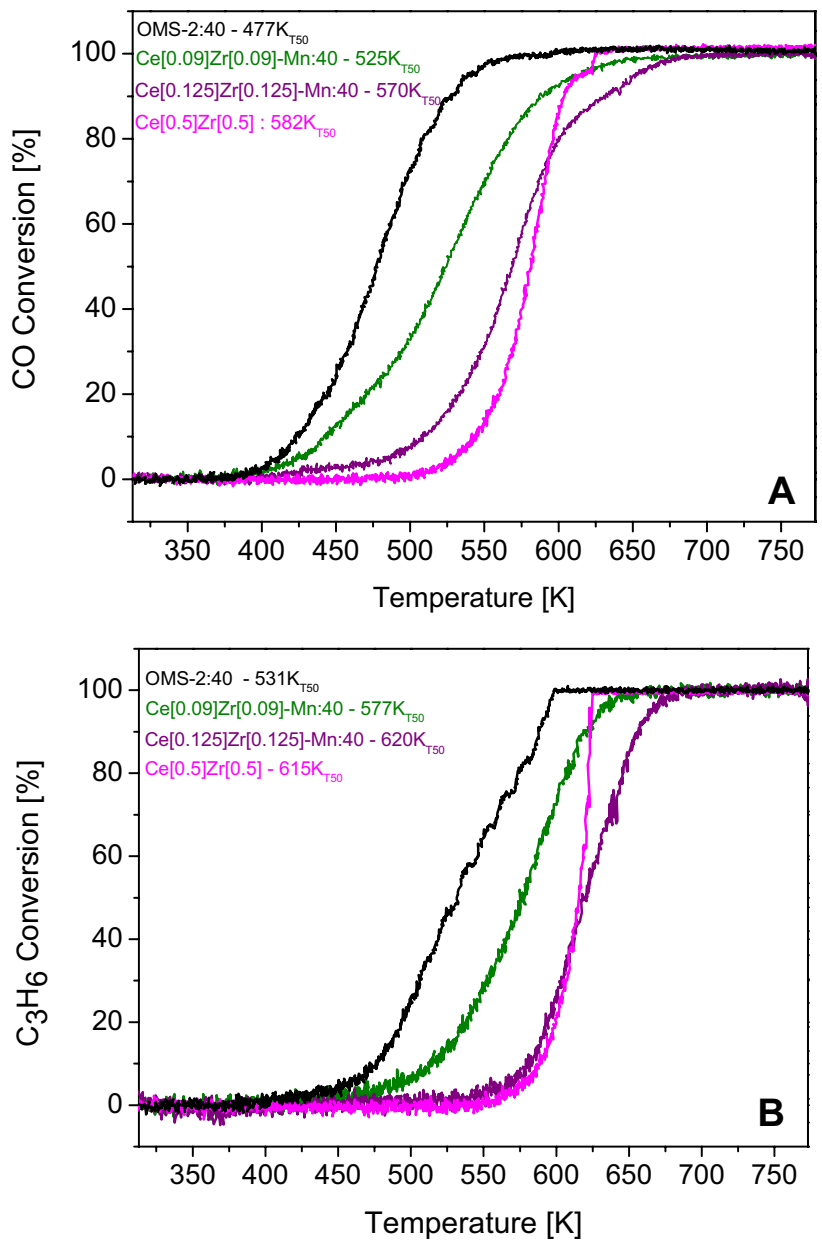

Fig. 6 Comparison of $\mathrm{CO}$ conversion (a) and $\mathrm{C}_{3} \mathrm{H}_{6}$ conversion (b) obtained over OMS-2:40 and $\mathrm{Ce} / \mathrm{Zr} / \mathrm{Mn}$ samples synthesised for 40 min 
a detrimental effect on the activity of the 40 min samples. An increase in $\mathrm{CO} \mathrm{T}_{50}$ value of $93 \mathrm{~K}$ was observed between $\mathrm{Ce}[0.09] \mathrm{Zr}[0.09]-\mathrm{Mn}: 40$ and OMS-2:40 and an increase of $86 \mathrm{~K}$ was noted between the corresponding $60 \mathrm{~min}$ samples. The $\mathrm{C}_{3} \mathrm{H}_{6} \mathrm{~T}_{50}$ value also increased by $46 \mathrm{~K}$ between $\mathrm{Ce}[0.09] \mathrm{Zr}[0.09]-\mathrm{Mn}: 40$ and OMS-2:40, while an increase of $92 \mathrm{~K}$ was observed between the corresponding $60 \mathrm{~min}$ samples. However, all newly the synthesised $\mathrm{Ce} / \mathrm{Zr} / \mathrm{Mn}$ materials showed a decrease in CO light-off compared to the commercial $\mathrm{Ce}[0.5] \mathrm{Zr}[0.5]$ catalyst (almost $40 \mathrm{~K}$ for the $\mathrm{Ce}[0.09] \mathrm{Zr}[0.09]-\mathrm{Mn}: 40$ sample and $20 \mathrm{~K}$ for the $\mathrm{Ce}[0.125]$ $\mathrm{Zr}[0.125]-\mathrm{Mn}: 60)$.

The negative effect on the oxidation activity of the addition of $\mathrm{Ce} / \mathrm{Zr}$ to the manganese oxide samples can be explained by considering Ce/Mn mole ratio. The $\mathrm{Ce} / \mathrm{Zr} / \mathrm{Mn}$ catalysts prepared with a Ce/Mn mole ratio of 0.09 had a higher content of the more active Mn phase, than the samples prepared with the $\mathrm{Ce} / \mathrm{Mn}$ mole ratio of 0.125 which results in higher light-off temperatures. The same effect was noted for the addition of $\mathrm{Ce}[0.5] \mathrm{Zr}[0.5]$ to manganese oxide, which gave higher light-off temperatures compared to the OMS-2 samples.

The only results that do not follow the trend of the decrement of the light-off temperature with the manganese oxide content is represented by $\mathrm{Ce}[0.09] \mathrm{Zr}[0.09]-\mathrm{Mn}: 60$. This sample showed $\mathrm{CO}$ and $\mathrm{C}_{3} \mathrm{H}_{6}$ light-off temperatures slightly higher than the sample prepared using the same conditions, but with a higher Ce/Mn ratio (0.125). This can be explained by the considering the surface area measured for $\mathrm{Ce}[0.09]$ $\mathrm{Zr}[0.09]-\mathrm{Mn}: 60$, which is significantly lower than values measured for all other $\mathrm{Ce} / \mathrm{Zr} / \mathrm{Mn}$ materials $\left(62.9 \mathrm{~m}^{2} \mathrm{~g}^{-1}\right)$. As previously discussed in the introduction, the catalytic activity is directly related to the number of available oxygen vacancies and thus, the surface area is an important physical property of the material for the reaction. As reported in Table 1, all of the $\mathrm{Ce} / \mathrm{Zr} / \mathrm{Mn}$ catalysts had a greater surface areas than the commercial sample $\mathrm{Ce}[0.5] \mathrm{Zr}[0.5]$. This increase in surface area and presence of a manganese oxide phase in the $\mathrm{Ce} / \mathrm{Zr} / \mathrm{Mn}$ materials, can be related to the increase catalytic activity in $\mathrm{CO}$ oxidation.

\subsection{Effect of Pt Loading}

Samples of the manganese oxide catalysts which were synthesised using a stirring time of $40 \mathrm{~min}$ were assessed for the application as catalytic supports for emission control applications. The pure manganese oxide sample, the Ce/Mn and $\mathrm{Ce} / \mathrm{Zr} / \mathrm{Mn}$ materials which were synthesised using the highest $\mathrm{Ce} / \mathrm{Mn}$ mole ratios ( 0.25 and 0.125 respectively), were loaded with $1 \mathrm{wt} \% \mathrm{Pt}$. The same light-off test, as previously described, was carried out on each of the manganese oxide based catalyst after the Pt loading.
The light-off curves measured on the Pt loaded manganese oxide based samples were compared with those obtained over a commercial model automotive catalyst with a $1 \mathrm{wt} \% \mathrm{Pt}$ supported on $\mathrm{CeO}_{2} / \mathrm{ZrO}_{2}$. The $\mathrm{CeO}_{2}: \mathrm{ZrO}_{2}$ mole ratio of the model catalyst was $1: 1$ and the samples is denoted as Pt:Ce[0.5]Zr[0.5]. The light-off curves acquired over the Pt loaded catalysts are reported in Fig. 7. Figure 7a reports that the model catalyst ( $\mathrm{Pt}: \mathrm{Ce}[0.5] \mathrm{Zr}[0.5])$ showed the lowest catalytic activity compared to the manganese oxide and mixed oxide catalysts, providing a $\mathrm{CO} \mathrm{T}_{50}$ value of $506 \mathrm{~K}$. A reduction of $109 \mathrm{~K}$ in the $\mathrm{T}_{50}$ value of $\mathrm{CO}$ was achieved with Pt:Ce[0.25]-Mn:40, which gave a CO $\mathrm{T}_{50}$ of $397 \mathrm{~K}$. At this point it should be highlighted that $\mathrm{Ce}$ [0.25]-Mn:40, which was without Pt, provided a CO lightoff temperature of $427 \mathrm{~K}$ (Fig. 3a). Comparing this result to that observed over Pt:Ce[0.5]Zr[0.5] (the model catalyst) in Fig. 7a, it is noted that $\mathrm{Ce}[0.25]-\mathrm{Mn}: 40$ gave a $\mathrm{CO} \mathrm{T}_{50}$ value which was $79 \mathrm{~K}$ lower, despite having no Pt loading.
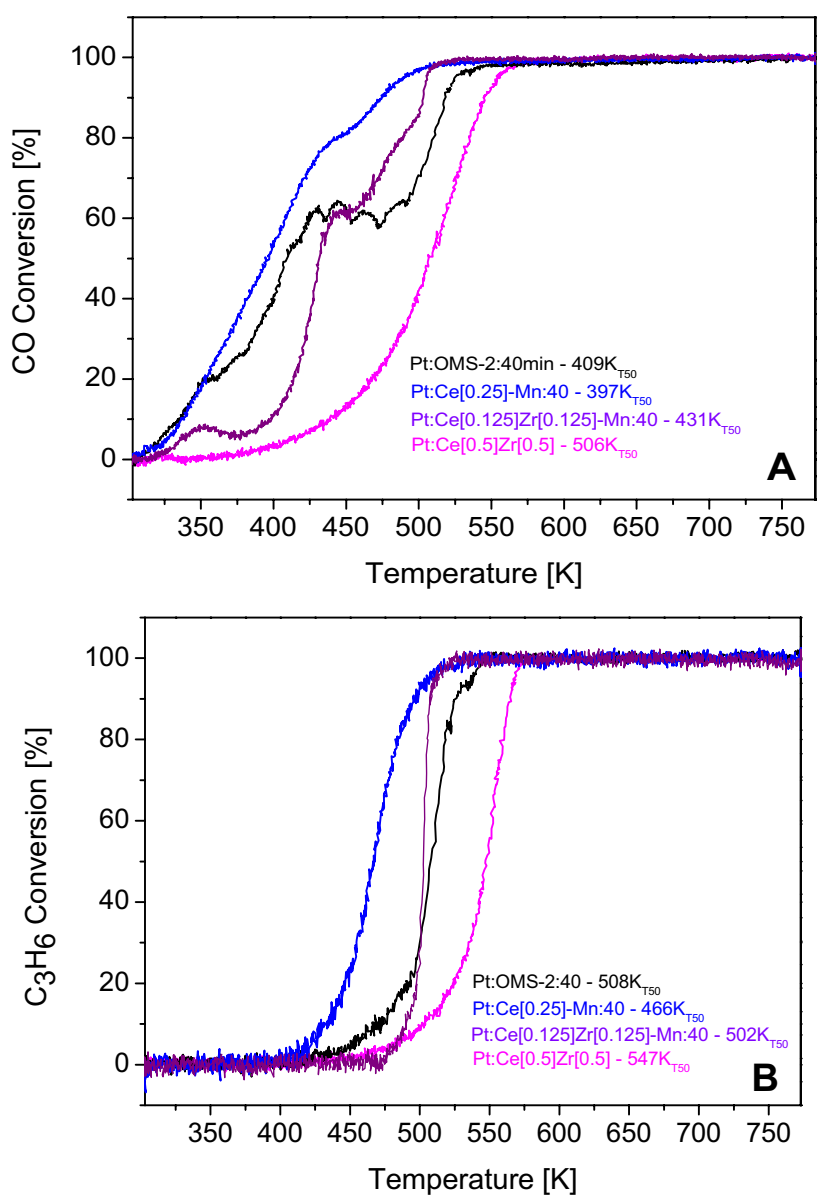

Fig. $7 \mathrm{CO}$ conversion (top) and $\mathrm{C}_{3} \mathrm{H}_{6}$ conversion (bottom) obtained over OMS-2:40, Ce[0.25]-Mn:40 and Ce[0.125][Zr[0.125]-Mn:40 samples which had been loaded with $1 \mathrm{wt} \% \mathrm{Pt}$, compared with a commercial $1 \mathrm{wt} \% \mathrm{Ce}_{0.5} \mathrm{Zr}_{0.5} \mathrm{O}_{2}$ catalyst 
A similar trend is reported in Fig. $7 \mathrm{~b}$ for $\mathrm{C}_{3} \mathrm{H}_{6}$ conversion which also shows that all manganese oxide based materials provided lower light-off temperatures than the commercial model catalyst, which gave a $\mathrm{C}_{3} \mathrm{H}_{6} \mathrm{~T}_{50}$ value of $547 \mathrm{~K}$. Pt:Ce[0.25]-Mn:40 also gave the lowest $\mathrm{C}_{3} \mathrm{H}_{6}$ light-off temperature of $466 \mathrm{~K}$, which was a reduction of $81 \mathrm{~K}$ compared to Pt: $\mathrm{Ce}[0.5] \mathrm{Zr}[0.5]$. It can also be noted that $\mathrm{Ce}[0.25]-$ $\mathrm{Mn}: 40$ gave a $\mathrm{C}_{3} \mathrm{H}_{6} \mathrm{~T}_{50}$ value of $479 \mathrm{~K}$. This is a reduction of $68 \mathrm{~K}$ compared to $\mathrm{C}_{3} \mathrm{H}_{6}$ light-off temperature achieved over the commercial Pt:Ce[0.5]Zr[0.5] sample, which had $\mathrm{C}_{3} \mathrm{H}_{6} \mathrm{~T}_{50}$ of $547 \mathrm{~K}$ (Fig. 7b), despite having no Pt loading.

As previously noted from Figs. 2 and 3, a reduction in the rate of $\mathrm{CO}$ oxidation was observed over the $\mathrm{Ce} / \mathrm{Mn}$ catalysts. This was attributed to the formation of intermediates during the oxidation of $\mathrm{C}_{3} \mathrm{H}_{6}$, which created competitive adsorption for active sites on the surface in the presence of NO. The same phenomenon can also be observed from the CO lightoff curves of the manganese based mixed oxide catalysts in Fig. 7a.

\section{Conclusion}

K-OMS-2 was synthesised using $60 \mathrm{~min}$ and $40 \mathrm{~min}$ sol-gel methods. A Cerium salt was introduced into the sol-gel synthesis route in order to synthesise amorphous $\mathrm{Ce} / \mathrm{Mn}$ mixed oxide catalysts, containing different $\mathrm{Ce} / \mathrm{Mn}$ mole ratios varied from 0.025 to 0.25 . Light-off test were carried on each sample and the results were compared with a crystalline manganese oxide sample (K-OMS-2). It was found that that addition of Ce resulted in an increase of surface area. In the catalyst with lower Ce/Mn ratios (0.025), the crystalline structure of OMS-2 was maintained. However, the addition of ceria to OMS-2 lead to a reduction in CO light-off temperatures of up to $40 \mathrm{~K}$. No effect was observed in the light-off temperature of $\mathrm{C}_{3} \mathrm{H}_{6}$. The further increase of $\mathrm{Ce} / \mathrm{Mn}$ ratio resulted in the absence of any crystalline phases in the synthesised materials. The amorphous $\mathrm{Ce} / \mathrm{Mn}$ materials also showed significantly higher surface areas compared to pure OMS-2. Catalytic testing also showed progressive decrement of $\mathrm{CO}$ and $\mathrm{C}_{3} \mathrm{H}_{6}$ light-off temperatures. A reduction in $\mathrm{CO}$ and $\mathrm{C}_{3} \mathrm{H}_{6}$ light-off of up to $70 \mathrm{~K}$ and $35 \mathrm{~K}$, respectively, were observed over the $60 \mathrm{~min}$ samples and a $50 \mathrm{~K}$ decrease of both species were noted over the $40 \mathrm{~min}$ samples. The difference in stirring times between 60 and $40 \mathrm{~min}$ in the synthesis of the Ce/Mn samples had no remarkable effect on the observed catalytic activity of the materials, although a correlation among the stirring time and the increment of surface area has been reported.

Cerium zirconium oxide $(\mathrm{Ce}[0.5] \mathrm{Zr}[0.5])$ was introduced into the $60 \mathrm{~min}$ and $40 \mathrm{~min}$ sol-gel method to synthesise $\mathrm{Ce} / \mathrm{Zr} / \mathrm{Mn}$ mixed oxide catalysts containing different $\mathrm{Ce} / \mathrm{Mn}$ mole ratios. It was found that the addition of low concentrations $\mathrm{Ce}[0.5] \mathrm{Zr}[0.5]$ resulted in a two phases material; a crystalline $\mathrm{Ce}[0.5] \mathrm{Zr}[0.5]$ phase and a crystalline OMS-2 phase were detected. However, it was observed that the increment in the content of the $\mathrm{Ce}[0.5]$ $\mathrm{Zr}[0.5]$ in the synthesis solution prevented the formation of the OMS-2 structure. The final material was, therefore, constituted by an amorphous Mn phase and a crystalline $\mathrm{Ce}[0.5] \mathrm{Zr}[0.5]$ phase. Furthermore, the addition of $\mathrm{Ce}[0.5] \mathrm{Zr}[0.5]$ in the sol-gel method provided materials with similar surface areas to the corresponding OMS-2 catalysts. Light-off tests also showed that the incorporation of $\mathrm{Ce}[0.5] \mathrm{Zr}[0.5]$ increased the $\mathrm{CO}$ and $\mathrm{C}_{3} \mathrm{H}_{6}$ light-off temperatures increased by between 50 and $90 \mathrm{~K}$ compared to pure OMS-2. It was observed that the light-off temperatures of both $\mathrm{CO}$ and $\mathrm{C}_{3} \mathrm{H}_{6}$ also increased at high $\mathrm{Ce} / \mathrm{Zr}$ / $\mathrm{Mn}$ ratio. This was attributed to the lower concentration of the active Mn phase in the samples which present a higher content of $\mathrm{Ce}[0.5] \mathrm{Zr}[0.5]$.

The effect of loading the synthesised catalysts with $\mathrm{Pt}$ was assessed. Samples from the materials synthesised using a stirring time of $40 \mathrm{~min}(\mathrm{OMS}-2: 40, \mathrm{Ce}[0.25]$ $\mathrm{Mn}: 40$ and $\mathrm{Ce}[0.125] \mathrm{Zr}[0.125]-\mathrm{Mn}: 40)$ were loaded with $1 \mathrm{wt} \% \mathrm{Pt}$ and compared with a commercially prepared $1 \mathrm{wt} \% \mathrm{Pt} \mathrm{Ce}{ }_{0.5} \mathrm{Zr}_{0.5} \mathrm{O}_{2}$ catalyst (Pt:Ce[0.5]Zr[0.5]). These results showed that the addition of $\mathrm{Pt}$ improved the performance of each catalyst, reducing both $\mathrm{CO}$ and $\mathrm{C}_{3} \mathrm{H}_{6}$ light-off temperatures. $\mathrm{CO}$ and $\mathrm{C}_{3} \mathrm{H}_{6}$ light-off temperature were reduced by $97 \mathrm{~K}$ and $39 \mathrm{~K}$ over Pt:Ce[0.25]-Mn:40 compared with Pt:Ce[0.5]Zr[0.5]. This can be attributed to the high surface area and amorphous nature of the active support (Ce[0.25]-Mn:40).

This work has shown that $\mathrm{Ce} / \mathrm{Mn}$ mixed oxides are highly effective catalysts for oxidation of $\mathrm{CO}$ and $\mathrm{C}_{3} \mathrm{H}_{6}$. It has also shown their success for the application of a support material for a diesel oxidation catalyst. The $\mathrm{Ce} /$ $\mathrm{Mn}$ mixed oxide catalysts, provided significantly lower $\mathrm{CO}$ and $\mathrm{C}_{3} \mathrm{H}_{6}$ light-off temperatures than a commercial diesel oxidation catalyst opening the prospect of using such materials for the low temperature oxidation of emissions from combustion engines.

\section{Compliance with Ethical Standards}

Conflict of interest Ruairi O'Donnell, Kathryn Ralphs, Maxime Grolleau, Haresh Manyar and Nancy Artioli declare that there are no conflict of interests.

Open Access This article is licensed under a Creative Commons Attribution 4.0 International License, which permits use, sharing, adaptation, distribution and reproduction in any medium or format, as long as you give appropriate credit to the original author(s) and the source, provide a link to the Creative Commons licence, and indicate if changes 
were made. The images or other third party material in this article are included in the article's Creative Commons licence, unless indicated otherwise in a credit line to the material. If material is not included in the article's Creative Commons licence and your intended use is not permitted by statutory regulation or exceeds the permitted use, you will need to obtain permission directly from the copyright holder. To view a copy of this licence, visit http://creativecommons.org/licenses/by/4.0/.

\section{References}

1. Adjimi S et al (2017) Highly efficient and stable Ru/K-OMS-2 catalyst for NO oxidation. Appl Catal B 219:459-466. https:// doi.org/10.1016/j.apcatb.2017.07.044

2. Almquist C, Krekeler M, Jiang L (2014) An investigation on the structure and catalytic activity of cryptomelane-type manganese oxide materials prepared by different synthesis routes. Chem Eng J 252:249-262. https://doi.org/10.1016/j.cej.2014.04.102

3. Aneggi $E$ et al (2006) Insights into the redox properties of ceria-based oxides and their implications in catalysis. J Alloys Compd 408-412:1096-1102. https://doi.org/10.1016/j.jallc om.2004.12.113

4. Aneggi E et al (2014) Shape-dependent activity of ceria in soot combustion. ACS Catal 4(1):172-181. https://doi.org/10.1021/ cs400850r

5. Bera $\mathrm{P}$ et al (2003) Promoting effect of $\mathrm{CeO}_{2}$ in combustion synthesized $\mathrm{Pt} / \mathrm{CeO}_{2}$ catalyst for $\mathrm{CO}$ oxidation'. J Phys Chem B 107(25):6122-6130. https://doi.org/10.1021/jp022132f

6. Brock SL et al (1998) A review of porous manganese oxide materials. Chem Mater 10(10):2619-2628. https://doi. org $/ 10.1021 / \mathrm{cm} 980227 \mathrm{~h}$

7. Buzková Arvajová A et al (2018) Modeling of two-step CO oxidation light-off on $\mathrm{Pt} / \Gamma-\mathrm{Al}_{2} \mathrm{O}_{3}$ in the presence of $\mathrm{C}_{3} \mathrm{H}_{6}$ and NOx. Appl Catal B 233(December 2017):167-174. https://doi. org/10.1016/j.apcatb.2018.03.081

8. Chen X et al (2019) Ce-Fe-Mn ternary mixed-oxide catalysts for catalytic decomposition of ozone at ambient temperatures. J Rare Earths. https://doi.org/10.1016/j.jre.2019.01.010

9. Ching $\mathrm{S}$ et al (1997) Sol-gel route to the tunneled manganese oxide cryptomelane. Chem Mater 4756(16):750-754. https:// doi.org/10.1021/cm960460k

10. Daneshvar K et al (2017) Experimental and modeling study of $\mathrm{CO}$ and hydrocarbons light-off on various $\mathrm{Pt}-\mathrm{Pd} / \gamma-\mathrm{Al}_{2} \mathrm{O}_{3}$ diesel oxidation catalysts. Chem Eng J 323:347-360. https://doi. org/10.1016/j.cej.2017.04.078

11. DeGuzman RN et al (1994) Synthesis and characterization of octahedral molecular sieves (OMS-2) having the hollandite structure. Chem Mater 6(6):815-821. https://doi.org/10.1021/ cm00042a019

12. Fino D et al (2016) A review on the catalytic combustion of soot in diesel particulate filters for automotive applications: from powder catalysts to structured reactors. Appl Catal A 509:7596. https://doi.org/10.1016/j.apcata.2015.10.016

13. Fu Z et al (2017) Catalytic oxidation of carbon monoxide, toluene, and ethyl acetate over the x Pd/OMS-2 catalysts: effect of Pd loading. Front Chem Sci Eng 11(2):185-196. https://doi. org/10.1007/s11705-017-1631-5

14. Gandhe AR et al (2007) Manganese oxide OMS-2 as an effective catalyst for total oxidation of ethyl acetate. Appl Catal B 72(1-2):129-135. https://doi.org/10.1016/j.apcatb.2006.10.017

15. Gorte RJ (2010) Ceria in catalysis: from automotive applications to the water-gas shift reaction. AIChE J. https://doi. org/10.1002/aic.12234

16. HapeshiTheocharisSolids ECRP (2008) Preparation, characterization of a cerium (IV)-incorporated manganese oxide OMS-2.
Effect of cerium (IV) template on octahedral molecular sieves of manganese oxide, characterization of manganese oxide molecular sieves with cerium (IV) as dopant. Adsorpt Sci Technol 26:789-801

17. Huang $\mathrm{H}$ et al (2015) Promoting effect of vanadium on catalytic activity of Pt/Ce-Zr-O diesel oxidation catalysts. J Environ Sci (China) 33(2005):135-142. https://doi.org/10.1016/j. jes.2014.10.026

18. Jakubek T et al (2019) Effect of noble metal addition to alkaliexchanged cryptomelane on the simultaneous soot and VOC combustion activity. Catal Commun 132(June):105807. https://doi. org/10.1016/j.catcom.2019.105807

19. Jan A et al (2019) Promotion of $\mathrm{Pt} / \mathrm{CeO}_{2}$ catalyst by hydrogen treatment for low-temperature $\mathrm{CO}$ oxidation. RSC Adv 9(46):27002-27012. https://doi.org/10.1039/c9ra05965b

20. Kamal MS, Razzak SA, Hossain MM (2016) Catalytic oxidation of volatile organic compounds (VOCs) - a review. Atmos Environ 140:117-134. https://doi.org/10.1016/j.atmosenv.2016.05.031

21. Kim MY et al (2016) Enhancing low-temperature activity and durability of Pd-based diesel oxidation catalysts using $\mathrm{ZrO}_{2}$ supports. Appl Catal B 187:181-194. https://doi.org/10.1016/j.apcat b.2016.01.023

22. King CK et al (2011) Manganese oxide octahedral molecular sieves (OMS-2) multiple framework substitutions: a new route to OMS-2 particle size and morphology control. Adv Funct Mater. https://doi.org/10.1002/adfm.201001020

23. Lavande NR, More RK, More PM (2020) Mg modified MnOx$\mathrm{CeO} 2-\delta$ catalyst for low temperature complete oxidation of simulated diesel engine exhaust. Appl Surf Sci. https://doi. org/10.1016/j.apsusc.2019.144299

24. Liotta LF (2010) Catalytic oxidation of volatile organic compounds on supported noble metals. Appl Catal B 100(3-4):403412. https://doi.org/10.1016/j.apcatb.2010.08.023

25. Liu Y et al (2009) 'Effects of surface area and oxygen vacancies on ceria in $\mathrm{CO}$ oxidation: differences and relationships. $\mathrm{J}$ Mol Catal A 316(1-2):59-64. https://doi.org/10.1016/j.molca ta.2009.09.022

26. Liu Y, Hou J (2019) Ce ion substitution position effect on catalytic activity of OMS-2 for benzene oxidation. Mater Res Bull 118(May):110497. https://doi.org/10.1016/j.materresbu 11.2019 .110497

27. Montini T et al (2016) Fundamentals and catalytic applications of $\mathrm{CeO}_{2}$-based materials. Chem Rev 116(10):5987-6041. https:// doi.org/10.1021/acs.chemrev.5b00603

28. Neha, Prasad R, Vir Singh S (2020) Catalytic abatement of CO, $\mathrm{HCs}$ and soot emissions over spinel-based catalysts from diesel engines: an overview. J Environ Chem Eng 8(2):103627. https:// doi.org/10.1016/j.jece.2019.103627

29. Ozawa M (1998) Role of cerium-zirconium mixed oxides as catalysts for car pollution: a short review. J Alloys Compd 275277:886-890. https://doi.org/10.1016/S0925-8388(98)00477-0

30. Patterson MJ, Angove DE, Cant NW (2000) The effect of carbon monoxide on the oxidation of four $\mathrm{C} 6$ to $\mathrm{C} 8$ hydrocarbons over platinum, palladium and rhodium. Appl Catal B 26(1):47-57. https://doi.org/10.1016/S0926-3373(00)00110-7

31. Russell A, Epling WS (2011) Diesel oxidation catalysts. Catal Rev - Sci Eng 53(4):337-423. https://doi.org/10.1080/01614 940.2011.596429

32. Shelef M, McCabe RW (2000) Twenty-five years after introduction of automotive catalysts: what next? Catal Today 62(1):35-50. https://doi.org/10.1016/S0920-5861(00)00407-7

33. Tang $\mathrm{W}$ et al (2019) Ceria-based nanoflake arrays integrated on $3 \mathrm{D}$ cordierite honeycombs for efficient low-temperature diesel oxidation catalyst. Appl Catal B 245(45):623-634. https://doi. org/10.1016/j.apcatb.2019.01.028 
34. Tingting $Z$ et al (2014) Precious metal-support interaction in automotive exhaust catalysts. J Rare Earths 32(2):97-107. https://doi. org/10.1016/S1002-0721(14)60038-7

35. Wang R, Li J (2009) OMS-2 catalysts for formaldehyde oxidation: effects of $\mathrm{Ce}$ and $\mathrm{Pt}$ on structure and performance of the catalysts. Catal Lett 131(3-4):500-505. https://doi.org/10.1007/ s10562-009-9939-5

36. Wang R, Li J (2010) Effects of precursor and sulfation on OMS-2 catalyst for oxidation of ethanol and acetaldehyde at low temperatures. Environ Sci Technol 44(11):4282-4287. https://doi. org/10.1021/es100253c

37. Wasalathanthri ND et al (2017) Mesoporous manganese oxides for NO2 assisted catalytic soot oxidation. Appl Catal B 201(2):543551. https://doi.org/10.1016/j.apcatb.2016.08.052
38. Yu L et al (2011) Promoting effect of Ce in Ce/OMS-2 catalyst for catalytic combustion of dimethyl ether. Catal Lett. https://doi. org/10.1007/s10562-010-0475-0

39. Zhang Q, Liu Q, Ning P (2017) Performance and kinetic study on $\mathrm{Pd} / \mathrm{OMS}-2$ catalyst for $\mathrm{CO}$ catalytic oxidation: effect of preparation method. Res Chem Intermed 43(4):2017-2032. https://doi. org/10.1007/s11164-016-2743-0

Publisher's Note Springer Nature remains neutral with regard to jurisdictional claims in published maps and institutional affiliations. 